\title{
RANCANG BANGUN APLIKASI RENTAL ALAT-ALAT PESTA DENGAN SISTEM NOTIFIKASI
}

\author{
Mohammad Faishol Zuhri ${ }^{1)}$ Siti Sufaidah ${ }^{2)}$ Agus Sifaunajah ${ }^{3)}$ \\ ${ }^{1,2,3)}$ Fakultas Teknologi Informasi Universitas KH.A. Wahab Hasbullah \\ Correspondence Author: agus.syifa85@gmail.com
}

\begin{abstract}
Basically, every rental service is a business that serves to maintain, manage, and utilize rental tools that are then provided to customers. The development of this company, the need for technology is needed to support the work of the system to more quickly and efficiently in processing letters, bill notes and notes change goods, and displays notification information in the form of schedule events to facilitate the provision of information directly to all employees. Current conditions in the rental SUYONO in running its business activities have not used the information system technology so that in the operation of the operational activities are still slow. SUYONO rental requires an information system which will support its business activities. Information System users are not only used in information and communications technology (ICT) organizations but also used by companies to support their business activities. From some shortcomings that exist in the company then the researcher is interested to make a Rental Apparatus Party with the Notification System, so the rental SUYONO in performing its operations more easily and quickly. The existence of the application of party equipment rental can help SUYONO rental to process the data in accordance with the necessary needs, as well as Output results in the form of travel documents, the bill notes, change notes, and billing reports can speed up the presentation process. With the notification in the form of event schedule information displayed on the second screen can facilitate both for employees and office staff in providing information on the event schedule directly.
\end{abstract}

Keywords: Information Systems, Party Equipment Rental, Notifications, SUYONO

\section{INTISARI}

Pada dasarnya setiap jasa penyewaan merupakan suatu usaha yang berfungsi untuk memelihara, mengelola, dan mendayagunakan alat-alat penyewaan yang kemudian disediakan kepada pelanggan. Semakin berkembangnya perusahaan ini, maka kebutuhan teknologi semakin diperlukan untuk menunjang kerja sistem agar lebih cepat dan efisien dalam memproses surat jalan, nota tagihan maupun nota ganti barang, serta menampilkan notifikasi informasi berupa jadwal acara agar mempermudah dalam pemberian informasi secara langsung kepada seтиa karyawan. Kondisi saat ini di persewaan SUYONO dalam menjalankan aktivitas usahanya belum menggunakan teknologi sistem informasi sehingga dalam pengerjaan kegiatan operasional tersebut masih lamban. Persewaan SUYONO membutuhkan sistem informasi yang mana akan mendukung kegiatan usahanya. Pengguna Sistem Informasi ini tidak hanya digunakan pada organisasi teknologi informasi dan komunikasi (TIK), namun juga digunakan oleh perusahaan untuk mendukung aktivitas bisnisnya. Dari beberapa kekurangan yang ada di perusahaan tersebut maka peneliti tertarik untuk membuat Aplikasi Rental Alat Pesta dengan Sistem Notifikasi, agar persewaan SUYONO dalam melakukan kegiatan operasionalnya lebih mudah dan cepat. Adanya aplikasi rental alat pesta dapat membantu Persewaan SUYONO untuk mengolah data sesuai dengan kebutuhan yang diperlukan, serta hasil Output berupa surat jalan, nota tagihan, nota ganti, dan laporan tagihan dapat mempercepat proses penyajian. Dengan adanya notifikasi berupa informasi jadwal acara yang ditampilkan pada layar kedua dapat mempermudah baik bagi karyawan maupun staff official dalam memberikan informasi jadwal acara secara langsung. 


\section{Kata Kunci : Sistem Informasi, Rental Alat Pesta, Notifikasi, SUYONO}

\section{Pendahuluan}

Persewaan SUYONO merupakan salah satu perusahaan jasa yang bergerak di bidang persewaan alat-alat pesta yang terletak di Jl. Ciwulan No 9A, Kec. Blimbing-Malang. Perusahaan ini menyediakan berbagai peralatan pesta, seperti: piring, gelas, sendok, mangkok, dan lain-lain. Perusahaan ini menyewakan peralatan pesta tersebut untuk keperluan berbagai acara diantaranya pesta pernikahan, perayaan hari besar, perpisahan sekolah dan lainnya. Pada dasarnya setiap perusahaan jasa penyewaan merupakan suatu usaha yang berfungsi untuk memelihara, mengelola, mendayagunakan alat-alat penyewaan yang kemudian disediakan kepada pelanggan (pengguna jasa).

Kondisi saat ini di Persewaan SUYONO dalam pengerjaan akivitas usahanya belum menggunakan teknologi informasi, sehingga kegiatan operasinal perusahaan tersebut masih lamban dalam hal pengolahan data. Masih lambannya dalam pengolahan data terhadap kegiatan operasional pada Persewaan Suyono tersebut terjadi seperti :

1. Tidak adanya teknologi pendukung untuk perhitungan nota tagihan.

2. Tidak adanya teknologi pendukung untuk penulisan surat jalan.

3. Tidak adanya teknologi pendukung untuk melakukan stock opname.

4. Tidak adanya notifikasi jadwal acara dalam pemberian informasi.

Dari beberapa contoh diatas dapat disimpulkan bahwa Persewaan SUYONO tidak melakukan kegiatan usahanya dengan efektif dan efisien. Sehingga Persewaan SUYONO membutuhkan sistem informasi yang mana akan mendukung kegiatan usahanya. Sistem Informasi merupakan sebuah teknologi dimana semua orang dalam melakukan aktivitasnya selalu menggunakan teknologi tersebut untuk mendukung operasional dan manajemen. Pengguna Sistem Informasi ini tidak hanya digunakan pada organisasi teknologi informasi dan komunikasi (TIK), namun juga digunakan oleh perusahaan untuk mendukung aktivitas bisnisnya.

Dari beberapa hal diatas, maka peneliti tertarik untuk membuat Rancang Bangun Aplikasi Rental Alat Pesta dengan Sistem Notifikasi, agar persewaan SUYONO dalam melakukan kegiatan operasionalnya lebih mudah dan cepat.

\section{Kerangka Teori}

\subsection{Landasan Teori}

\subsubsection{Pengertian Perancangan}

Soetam Rizky (2011) mendefinisikan bahwa perancangan adalah sebuah proses untuk mendefinisikan sesuatu yang melibatkan deskripsi mengenai arsitektur serta komponen. Dalam sebuah perancangan juga terdapat beberapa tujuan untuk mencapai target tertentu.

Tujuan sebuah perancangan menurut Andri Koniyo (2007) antara :

a. Memenuhi spesifikasi fungsional.

b. Memenuhi batasan-batasan media target implementasi, target sistem komputer.

c. Memenuhi kebutuhan-kebutuhan implisit dan eksplisit berdasarkan kinerja dan penggunaan sumber daya.

d. Memenuhi kebutuhan-kebutuhan implisit dan eksplisit berdasarkan bentuk hasil rancangan yang dikehendaki.

e. Memenuhi keterbatasan-keterbatasan proses perancangan seperti lama atau biaya.

f. Untuk memberikan gambaran yang jelas dan rancangan bangun yang lengkap kepada pemrogram komputer dan teknik ahli lainnya yang terlibat.

g. Untuk tercapainya pemenuhan kebutuhan berkaitan dengan pemecahan masalah yang menjadi sasaran pengembangan sistem.

h. Untuk kemudahan dalam proses pembuatan software dan control dalam sistem yang dibangun.

i. Untuk kemaksimalan solusi yang diusulkan melalui pengembangan sistem. 
j. Untuk dapat mengetahui berbagai elemen spesifik pendukung dalam pengembangan sistem baik berupa perangkat lunak maupun perangkat keras yang digunakan pada sistem yang di desain.

\subsubsection{Pengertian Rental}

Menurut Schneider (2004), rental (Manajemen jasa) adalah suatu bidang yang mengedepankan berbagai disiplin dalam sebuah praktik dan riset yang berkenaan dengan kualitas jasa. Gonroos (2000), mendeskripsikan empat elemen utama dalam manajemen jasa :

1. Pemahaman nilai-nilai yang meliputi kualitas dan kepuasan yang didapat dari Customer melalui jasa yang sudah digunakan.

2. Pemahaman atas kemampuan organisasi, baik didapat melalui : SDM, teknologi, sumber daya fisik, sistem, dan pelanggan. dengan hal tersebut maka dalam menghasilkan, menyampaikan nilai, dan persepsi kualitas dapat diperoleh dari berbagai organisasi tersebut.

3. Pemahaman perkembangan yang didapat dengan cara mengembangkan dan mengelola organisasi dapat menjadikan nilai dan persepsi kualitas yang sesuai harapan.

4. Menjalankan organisasi sedemikian rupa dengan harapan agar nilai dan persepsi kualitas bisa diwujudkan oleh semua pihak dengan pencapaian yang diinginkan. (Fandi Tjiptono dan Gregorius Chandra, 2005)

\subsubsection{Konsep Basis Data}

Dalam peranannya, Database merupakan suatu komponen yang sangat diperlukan dalam mengolah sebuah data. Menurut Fatansyah (2012), Sebagai satu kesatuan istilah, basis data (Database) sendiri dapat didefinisikan dalam sejumlah sudut pandang seperti:

- Himpunan kelompok data (arsip) yang saling berhubungan yang diorganisasi sedemikian rupa agar kelak dapat dimanfaatkan kembali dengan cepat dan mudah.

- Kumpulan data yang saling berhubungan yang disimpan secara bersama sedemikian rupa dan tanpa pengulangan (redudansi) yang tidak perlu, untuk memenuhi berbagai kebutuhan.

- Kumpulan file/table/arsip yang saling berhubungan yang disimpan dalam media penyimpanan elektronik.

Dari kutipan tersebut dapat diketahui bahwa Database sangatlah penting dalam proses pengolahan data untuk memenuhi berbagai kebutuhan. dalam pembuatan aplikasi ini peneliti menggunakan Database Mysql sebagai tempat penyimpanan data.

\subsubsection{Database Relational}

Dalam bukunya, Fathansyah (2012) mengemukakan bahwa Database Relational merupakan relasi yang menunjukkan adanya hubungan diantara sejumlah entitas yang berasal dari himpunan entitas yang berada. Misalnya, entitas item barang dengan kode ='BRG001' dan nama_barang ='Piring makan' mempunyai relasi dengan entitas sebuah group barang dengan Kode ='GB001' dan nama_group ='Piring'. Relasi diantara kedua entitas tadi mengandung arti bahwa item barang tersebut merupakan bagian dari group piring.

\subsection{5. $M Y S Q L$}

Abdul Kadir (2008), MYSQL adalah salah satu jenis database server yang sangat terkenal. Kepopulerannya disebabkan karena MYSQL menggunakan SQL sebagai bahasa dasaruntuk mengakses databasenya. Selain itu ia juga bersifat open source padaberbagai platform.

Sedang menurut Anhar (2010), MYSQL (My Structure Query Language) adalah salah satu Database Management System (DBMS) dari sekian banyak DBMS seperti Oracle, MS SQL, Portage $S Q L$, dan lainnya. MYSQL berfungsi untuk mengolah database menggunakan bahasa $S Q L$. $M Y S Q L$ juga bersifat Open source sehingga kita menggunakannya secara gratis.

\subsection{Pustaka Rujukan}

Dalam Penulisan Skripsi ini peneliti menggali informasi dari penelitian-penelitian sebelumnya sebagai bahan perbandingan, baik mengenai kekurangan atau kelebihan yang sudah ada. Selain itu, peneliti juga menggali informasi dari buku-buku maupun skripsi dalam rangka mendapatkan suatu 
informasi yang ada sebelumnya tentang teori yang berkaitan dengan judul yang digunakan untuk memperoleh landasan teori ilmiah.

1. Jurnal Wendi Wirasta, Mahasiswa program studi Sistem Informasi STMIK LPKIA tahun ajaran 2014 dengan judul "Perancangan Sistem Informasi Penyewaan Alat-alat Pesta Berbasis WEB di Narda Pesta".

2. Jurnal Rino Ade Lesmana Wijaya, Mahasiswa jurusan Sistem Informasi Universitas Komputer Indonesia dengan judul "Sistem Informasi Penyewaan Alat Pesta Pada Saung Kuring di Cidaun Berbasis WEB".

3. Jurnal Awan Firmansayah, Mahasiswa jurusan Sistem Informasi STIKOM Surabaya dengan judul "Rancang Bangun Aplikasi Pelayanan Persewaan Alat-alat Pesta Berbasis WEB".

Jurnal Dwi Wicaksono Ekosari, Mahasiswa jurusan Sistem Informasi Universitas Dian Nuswantoro Semarang dengan judul "Sistem Informasi Persewaan Alat Pesta Berbasis WEB pada CV. Tri Manuggal di Unggaran".

\section{Metodologi}

\subsection{Analisis Kebutuhan Sistem}

\subsubsection{Kebutuhan Perangkat Keras}

Dalam membuat suatu aplikasi yang perlu diperhatikan adalah bagaimana aplikasi tersebut dapat dijalankan di komputer yang memiliki spesifikasi tertentu. Standar spesifikasi yang digunakan untuk menjalankan program adalah :

1. Intel ${ }^{\circledR}$ Atom ${ }^{\mathrm{TM}} \mathrm{CPU} \mathrm{N} 570 @ 1.67 \mathrm{GHz}$

2. VGA 1024 x 600

3. 2 GB RAM

\subsubsection{Kebutuhan Perangkat Lunak}

Untuk kelengkapan agar dapat dibuatnya aplikasi tersebut, maka dibutuhkanlah perangkat lunak tambahan, seperti:

1. XAMPP 1.8.3

2. Crystal Report 8.5

3. Microsoft Visual Basic 6.0

\subsection{Perancangan Sistem}

\subsubsection{FlowChart}

Dalam perancangan sebuah sistem, penulis membuat Flowchart untuk mempermudah dalam pemecahan masalah yang terbagi ke dalam Segmen-segmen kecil sehingga dapat membantu dalam proses analisa. Dalam bukunya Krismiaji (2010) menerangkan bahwa flowchart merupakan teknik analitis yang digunakan untuk menjelaskan aspek-aspek sistem informasi secara jelas, tepat dan logis. Berikut alur program secara umum:

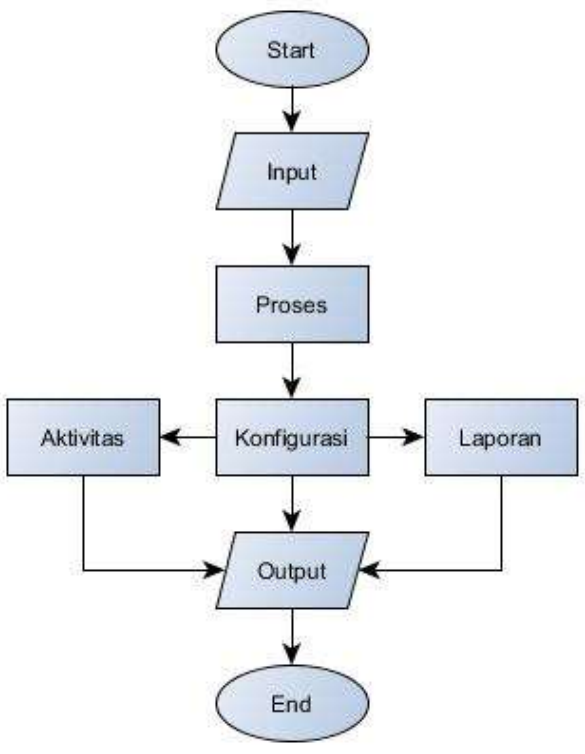


Gambar 1 : Flowchart secara umum

\section{Keterangan :}

a. Input

Pertama kali program dijalankan tampil sebuah form Login. Jika login gagal akan ada perintah untuk mengulang login, baik karena kesalahan dalam memasukan Username atau Password. jika login berhasil akan keluar tampilan Menu utama.

b. Proses

Dalam sebuah proses terdapat menu utama terdiri dari menu "Transaksi, Konfigurasi, dan Laporan".

1) Menu Aktivitas

Dalam menu ini terdapat sub menu "Transaksi Sewa, Ganti Barang, Pelanggan dan Stock Opname".

2) Menu Konfigurasi

Dalam menu ini terdapat sub menu "Item barang, group barang, Back up Database, dan Hak akses".

3) Menu Laporan

Dalam menu ini terdapat berbagai laporan seperti : laporan pelanggan, laporan item barang, dan laporan rekap tagihan.

c. Output

Terdapat berbagai macam output, seperti : nota sewa, nota ganti rugi, laporan item barang, laporan pelanggan, dan laporan tagihan.

\subsubsection{Data Flow Diagram}

Al-Bahra bin Ladjamudin (2005) menerangkan bahwa Data Flow Diagram (DFD) merupakan model dari sistem untuk mengambarkan pembagian sistem ke modul yang lebih kecil.

Data Flow Diagram (DFD) adalah suatu model logika data atau proses yang dibuat untuk menggambarkan dari mana asal data, dan kemana tujuan data yang keluar dari sistem, dimana data disimpan, proses apa yang menghasilkan data tersebut, dan interaksi antar data yang tersimpan, dan proses yang dikenakan pada data tersebut (Kristanto, 2008).

\subsubsection{Diagram Konteks}

Diagram konteks memberikan gambaran umum terhadap kegiatan dalam sistem.

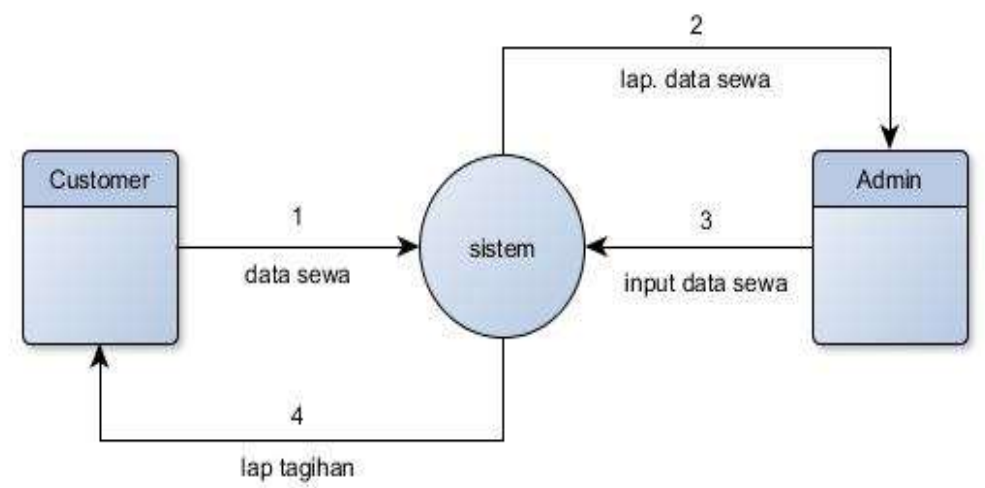

Gambar 2 : Diagram Konteks

Keterangan :

Data Flow Diagram menjelaskan tentang bagaimana gambaran secara umum alur program. Dari penjelasan Gambar 3.7 diatas terdapat 4 keterangan sebagai berikut :

1. Customer memberi data sewa kepada system 
2. Sistem memberi laporan kepada admin berupa data sewa

3. Admin meng-input data sewa

4. Customer mendapat laporan berupa nota tagihan

4. Hasil dan Pembahasan

\subsection{Perancangan Interface Aplikasi}

1. Sewa Peralatan

Form memproses berbagai kegiatan kerja dalam sistem, seperti : surat jalan dan nota tagihan.

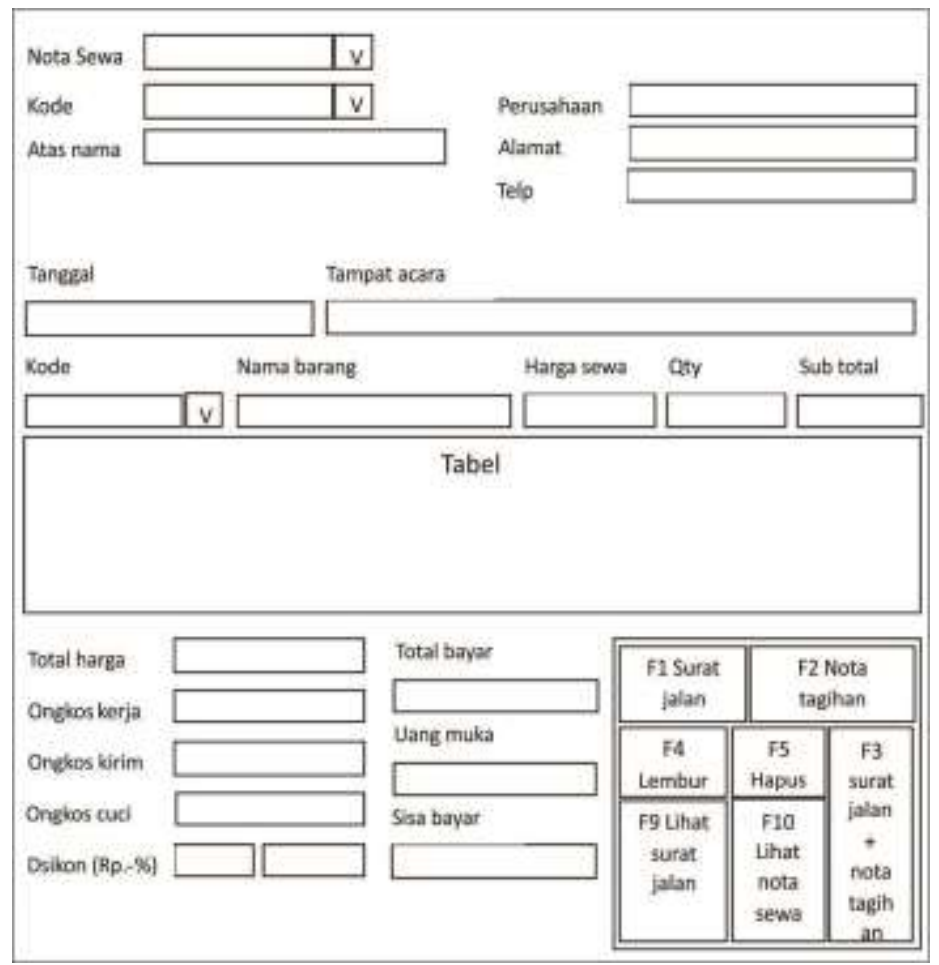

Gambar 3 : Perancangan Form Sewa Peralatan

2. Ganti Barang

Form ganti barang merupakan suatu proses dimana ketika barang yang disewa oleh customer hilang/rusak. Maka form ini digunakan untuk memproses nota ganti.

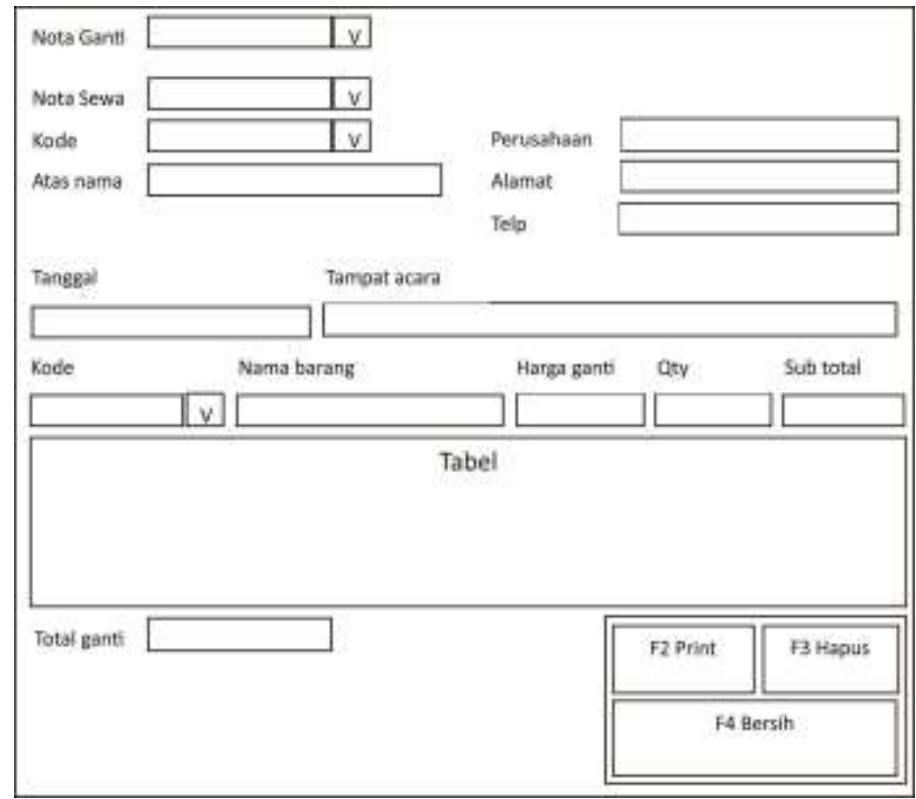




\section{Gambar 4 : Perancangan Form Ganti Barang}

3. Notifikasi Jadwal Acara

Form ini digunakan untuk melihat jadwal acara sekaligus tampilan yang akan ditampilkan pada notifikasi layar ke dua.

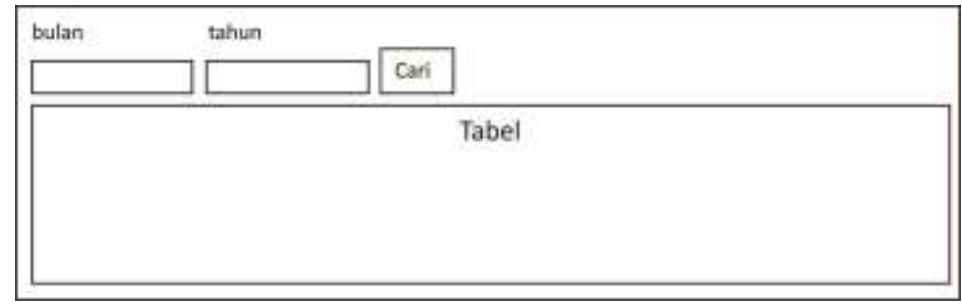

\section{Gambar 5 : Perancangan Form Notifikasi Jadwal Acara}

\subsection{Hasil Interface Aplikasi}

Setelah dilakukan perancangan interface, dilakukan pengujian untuk melihat apakah hasil perancangan dapat berjalan sesuai harapan. Adapun sebagian hasil yang didapatkan adalah sebagai berikut :

1. Sewa Peralatan

Form memproses berbagai kegiatan kerja dalam sistem, seperti : surat jalan dan nota tagihan.

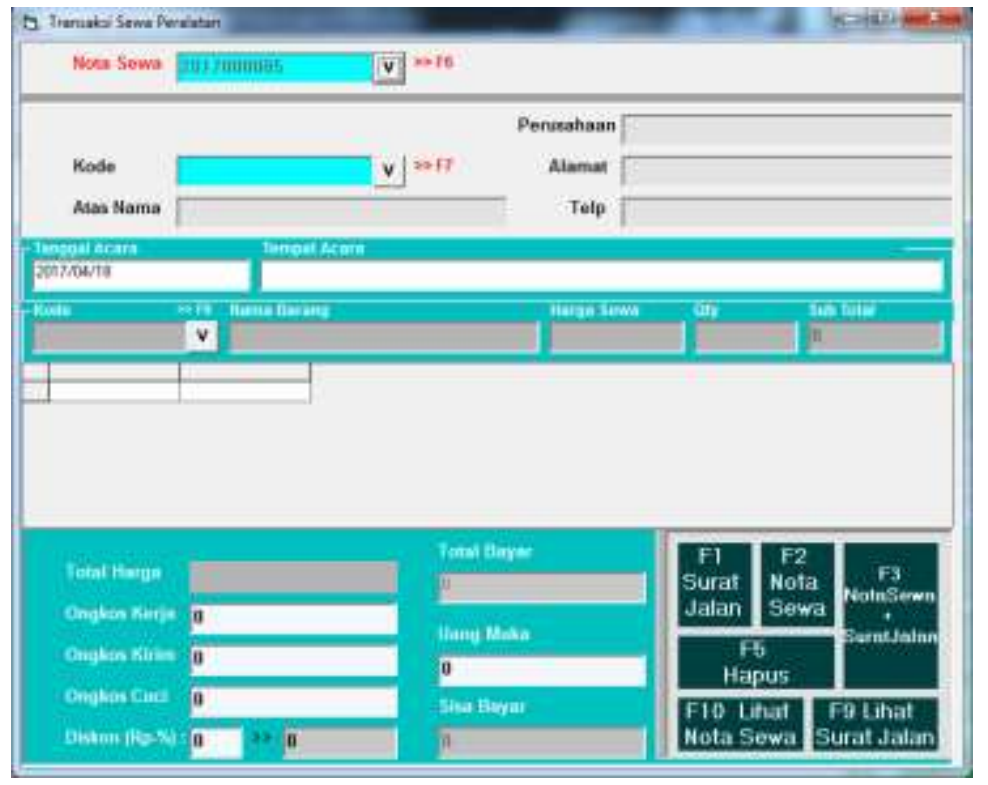

Gambar 6 : Form Sewa Peralatan

5. Ganti Barang

Form ganti barang merupakan suatu proses dimana ketika barang yang disewa oleh customer hilang/rusak. Maka form ini digunakan untuk memproses nota ganti. 


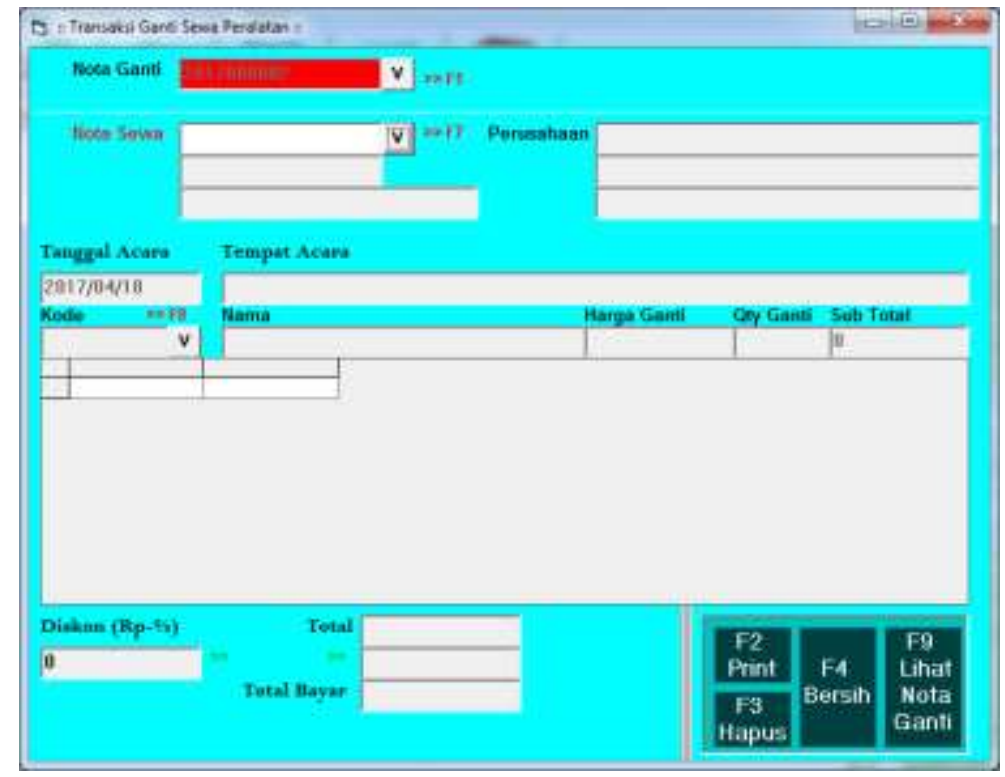

6. Notifikasi Jadwal Acara

Gambar 7 : Form Ganti Barang

Form ini digunakan untuk melihat jadwal acara sekaligus tampilan yang akan ditampilkan pada notifikasi layar ke dua.

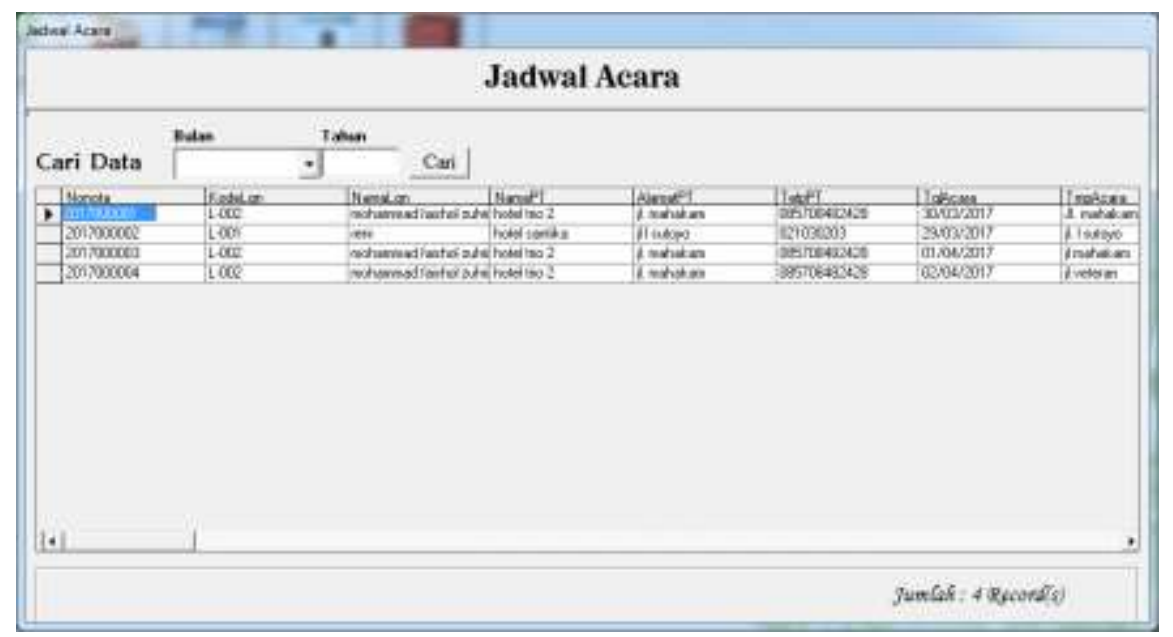

Gambar 8 : Form Notifikasi Jadwal Acara

\section{Penutup}

\subsection{Kesimpulan} berikut:

Dari analisa data yang sudah diperoleh, maka dapat ditarik beberapa kesimpulan sebagai

1. Adanya aplikasi Rental alat pesta dapat membantu Persewaan SUYONO untuk mengolah data sesuai dengan kebutuhan yang diperlukan.

2. Hasil Output berupa Surat Jalan, Nota Tagihan, Nota Ganti, dan Laporan Tagihan dapat mempercepat proses penyajian.

3. Notifikasi berupa informasi jadwal acara yang ditampilkan pada layar kedua dapat mempermudah baik bagi karyawan maupun staff official dalam memberikan informasi jadwal acara secara langsung. 


\subsection{Saran}

Adapun saran-saran yang dapat penulis berikan dengan harapan agar aplikasi ini bisa dikembangkan lebih baik lagi. Agar lebih sempurnanya aplikasi ini terdapat berbagai kekurangankekurangan seperti fitur-fitur sebagai berikut :

1. Form karyawan, untuk mengolah data karyawan.

2. Form penggajian, untuk mengolah proses penggajian karyawan.

3. Form lembur, untuk menghitung proses lembur karyawan.

4. Form bond, untuk menghitung proses bond karyawan.

5. Dan form cashflow, untuk mengolah data keuangan. 


\section{DAFTAR PUSTAKA}

Abdul Kadir. 2008. Dasar Pemrograman WEB Dinamis Menggunakan PHP. Yogyakarta : Andi. Al-Bahra bin Ladjamudin. 2005. Analisis dan Desain Sistem Informasi. Yogyakarta : Graha Ilmu. Anhar. 2010. Panduan Menguasai PHP \& MYSQL Secara Otodidak. Jakarta : Mediakita.

Edy Winarno, et. al. 2013. Belajar Pemrograman VB6 dalam Sekejap. Jakarta : PT Elex Media Komputindo.

Fatansyah. 2012. Basis Data. Bandung : Informatika Bandung.

Irnwan, Yesni Malau. 2011 Apa Pun Permintaanya Crystalreport Jawabannya!. Jakarta : PT Elex Media Komputindo.

Kristanto, Andri. 2008. Perancangan Sistem Informasi dan Aplikasinya, Edisi Revisi. Yogyakarta : Gava Media.

Krismiaji. 2010. Sistem Informasi Akuntansi. Yogyakarta : UPP AMP YKPN.

Kusrini, Andri Koniyo. 2007. Petunjuk Instalasi Crystal Report. Yogyakarta : Jurusan Sistem Informasi STMIK AMIKOM

Rizky, Soetam. 2011. Konsep Dasar Rekayasa Perangkat Lunak. Jakarta: Prestasi Pustaka.

Wardana, S. 2010. Menjadi master PHP dengan framework CodeIgniter. Jakarta : Alex Media Komputindo. 